
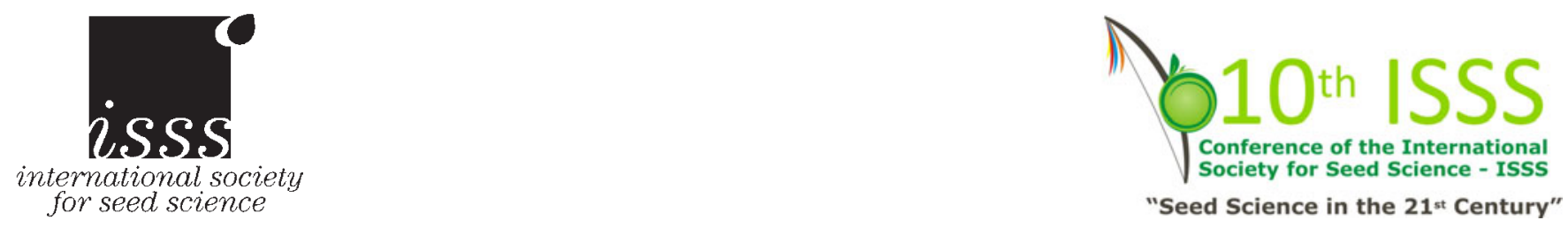

\title{
PREFACE
}

\section{Tenth International Conference on Seed Science: Seed science in the 21st century}

\author{
Costa du Sauipe, Brazil, 10-15 April 2011
}

The International Society for Seed Science (ISSS) is pleased to sponsor this Special Issue of Seed Science Research containing brief reviews of topics covered in invited lectures at the latest in our series of conferences 'Seed science in the 21st century'. The topics represent the broad spectrum of seed science presented at this 10th triennial conference and the innovative seed science that is promoted by our society. This successful conference allowed scientists from all around the world to present and discuss their results on many aspects of seed science at the molecular, through whole seed to ecological levels, and from basic science to advances in seed technology. It is the strength of this series of conferences that scientists interested in seeds can update themselves on the wide range of techniques and approaches that can be applied to seed research.

This Special Issue is in keeping with the objectives of the ISSS to promote our fascination with seeds and how they function, at both ends of the plant's life cycle, and I would like to thank the editor, Henk Hilhorst, for bringing it together. We hope that it will encourage readers to attend future ISSS conferences and workshops. The next conference will be held in Chansha, China, September 2014, with earlier, more specialized workshops on Molecular aspects of germination and dormancy (Paris, France, July 2013) and Seed ecology (Shenyang, China, June 2013).

Bill Finch-Savage

President ISSS

The 10th International Conference on Seed Science was held from 10 to 15 April 2011, in Costa do Sauipe, Salvador, Brazil. The conference was co-promoted by the ISSS and the Federal University of Bahia, and brought together over 400 delegates from 24 countries. The programme consisted of 450 scientific presentations, both oral and posters, from which key papers were selected for this Special Issue of Seed Science Research.

The conference provided a platform for the scientific exchange of ideas, methods and technologies among representatives of the entire seed supply chain, involving seed biology and technology of native, model and crop species. The scope of the meeting, 'Seed science in the 21st century' was served by a high-profile programme as the basis for a plenary debate on the future of seed science in relation to agricultural demands, plant biodiversity and global climate change.

The conference co-hosted a joint session of the International Seed Testing Association (ISTA) and the Brazilian Seed Association (ABRATES) on 'Practical applications of science and technology in seeds'.

Last but not least, along with inivited speakers and delegates, the contributions from public and private sponsors was crucial for the success of the conference.

Our sincere thanks,

Renato D. de Castro

Chair

Luzimar G. Fernandez

Co-chair 
Compiling and editing this Special Issue was a joy and I hope it will be well read by the seed science community. It is intended to place seed science in its deserved perspective of important issues in agriculture and biodiversity, including global climate change and the feeding of an increasing world population.

I thank all the authors for their excellent contributions and their cooperation when revisions were necessary. I am also grateful to the reviewers who responded positively to evaluate the manuscripts within the allocated time. Thanks are also due to the Editorial Office and Production Department of Cambridge University Press for their ample and kind support.

Henk Hilhorst

Editor-in-Chief 